\title{
Kentsel yeşil altyapı analizi: Bornova örneği
}

\section{Urban green infrastructure analysis: The case of Bornova}

\section{Çiğdem COŞKUN HEPCAN, Şerif HEPCAN}

Ege Üniversitesi Ziraat Fakültesi Peyzaj Mimarlı̆ğ Bölümü, 35100 Bornova İZMIR

Sorumlu yazar (Corresponding author): Ç. Coşkun Hepcan, e-posta (e-mail): cigdem.coskun.hepcan@ege.edu.tr

\section{MAKALE BILLGISİ}

Alınıs tarihi 17 Temmuz 2017

Düzeltilme tarihi 12 Aralık 2017

Kabul tarihi 08 Ocak 2018

\section{Anahtar Kelimeler:}

Kentsel açık yeșil alan

Peyzaj metrikleri

Bornova

\section{öz}

Bu araştırmada; Bornova kentsel peyzajı içindeki açık ve yeşil alanların strüktürünü ortaya koymak amacıyla, kentsel açık ve yeşil alan sisteminin bileşenleri olan doğal ve bitkilendirilmiş parça ve koridorlar, 2014 yılı arazi kullanım haritası kullanılarak tanımlanmıştır. Bu bileşenlerin strüktürü; sekiz adet peyzaj metriği (sınıf alanı (CA), parça sayısı (NP), peyzajın oranı (PLAND), Peyzaj şekil indeksi (LSI), ortalama parça büyüklüğü (AREA MN), yakınlık indeksi (PROX AM), süreklilik indeksi (GYRATE AM), mesafe indeksi (ENN_AM)) kullanılarak analiz edilmiştir. Araştırmada, kentsel açık ve yeşil alan sistemi oluşturma potansiyeline sahip parça ve koridorların kentsel gelişme alanı içindeki oranının \% 45 (\% 43 parça, \% 2 koridor) olduğu belirlenmiștir. Sonuçlar ayrıca kentsel gelişme alanı içinde düzensiz dağılım gösteren parça ve koridorların büyük ölçüde doğal karakterli olduğunu, aralarındaki mesafelerin fazla ve peyzajdaki sürekliliğinin düșük olduğu göstermiştir. Araştırma sonuçları; kentte bir yeşil alt yapı sisteminin bulunmadığını, niceliksel açıdan açık ve yeşil alanların kentsel peyzaj içindeki durumunun yeterli olmadığı, ancak kentin içinde olmasa da çeperlerinde gelecekte yeşil altyapı sistemi oluşturmak için uygun olarak kullanılması halinde kent ekosistemine daha çok katkı sağlayabilecek önemli yeşil alanlar bulunduğunu ortaya koymuştur.

\section{ARTICLE INFO}

Received 17 July 2017

Received in revised form 12 December 2017 Accepted 08 January 2018

\section{Keywords:}

Urban open and green area

Landscape metrics

Bornova

\begin{abstract}
In this study, natural and artificial patches and corridors as the elements of the urban green areas system were identified using land use map of the year of 2014 in order to reveal the structure of open and green spaces in the Bornova district. The structure of aforementioned elements of the open and green space system was analyzed using eight landscape metrics, which are Class Area (CA), Number of Patches (NP), Proportion of Landscape (PLAND), Landscape Shape Index (LSI), Mean Patch Size (AREA_MN), Mean Proximity index (PROX_AM), Radius of Gyration (GYRATE_AM) and Nearest Neighbor Distance (ENN_AM). It was determined that the ratio of potential elements of the open and green space system, patches and corridors in the urban development area was $45 \%$ (43\% patch, $2 \%$ corridor) in total. Moreover, patches and corridors with predominantly natural character were randomly scattered throughout the urban landscape and showed a very low continuity. In conclusion, there was no interconnected system of open and green spaces in the study area, quality and quantity of the existing urban open and green spaces were not very promising but there was an important reserve of open and green spaces on the fringes of the Bornova district that can be used for establishing a future green infrastructure.
\end{abstract}

\section{Giriş}

Açık-yeşil mekânlar kentsel peyzajların en önemli bileşenlerinden birisidir (Fung ve ark. 2008; Esbah ve ark. 2009; Hepcan 2013). Ekolojik ve rekreasyonel pek çok işlevi yerine getirirken, kentsel yaşam kalitesinin yükseltilmesine katkı yaparlar. Ancak yeşil alanlar dünyanın pek çok kentinde olduğu gibi ülkemiz kentlerinde de kentin ve kentlinin ihtiyaçları ile doğal peyzaj bileşenlerinin bir arada düşünüldüğü bir yaklaşımla bir planlama ürünü olarak değil, genellikle rastlantısal olarak üretilmektedir (Hepcan ve ark 2006; Steiner 2011; Hepcan 2013). Peyzaj bilinci gelişmemiş ülkelerde açık-yeşil alanların işlevi çoğu zaman boş-artık alanların süslenmesinden öteye geçememektedir (Steiner 2011).

Yeşil altyap1, kırsal ve kentsel peyzajlarda ekosistem servislerinin sağlanması ve biyolojik çeşitliliğin korunması amaciyla düzenlenen ve yönetilen doğal, yarı doğal ve kültürel alanların bütüncül olarak planlandığı bir ağ anlamına 
gelmektedir (Benedict 2000; European Commission 2013). "Ekolojik ağ" yaklaşımlarının bir alt birimi olarak ABD'de ortaya çıkan bu kavram, yeşil alan sistemi oluşturmayı hedeflemekte, kentsel bir yeşil omurga oluşturulmasında aktif rol oynamaktadır (Tokuş ve Eşbah 2010).

Yeşil altyapı planları bölge, alt bölge, semt ve mahalle ölçeğinde yapılabilir. Bölge ölçeğinde milli parklar gibi büyük korunan alanlar ve büyük nehir koridorları ele alınırken; alt bölge ölçeğinde kent korulukları, küçük ölçekli korunan alanlar, akarsu koridorları, rekreasyonel koridorlar, kıyı kumulları; semt ölçeğinde kent parkları, küçük akarsu-dere koridorları, oyun alanları, koruluklar, sulak alanlar ve mahalle ölçeğinde ise yol ağaçları, ev bahçeleri, mezarlıklar, küçük dereler ve tarım alanları gibi bileşenler plana dahil olur (Davies ve ark. 2015; European Environment Agency 2011).

Yeşil altyapı planlamasının amaçları; mevcut yeşil alanları değerlendirmek ve kaybını-tahribini önlemek, yeşil alanların kalitesini ve çeşitliliğini arttırmak, stratejik bağlamda yaklaşarak yeşil alanları birbiriyle bağlantı kılmak ve mülkiyetine bakılmaksızın bütün yeşil alanları dikkate almak olarak say1labilir (Davies ve ark. 2015).

Peyzaj yapısının (strüktür) analiz edilmesi, peyzajı oluşturan unsurlar arasındaki ilişkilerin açıklanması açısından önemlidir. Peyzaj yapısı ve fonksiyonu arasındaki ilişkinin ortaya konulması, planlanan aktivitelerin ekolojik sisteme olası etkilerini tahmin etmede ve bu yönde planlama kararlarını yönlendirmede rol oynayabilir (Botequilha Leitao ve ark. 2006). Peyzaj analizi sonuçları diğer planlama çalışmalarının yanında yeşil altyapı planlarına altlık sağlamaktadır.

Kent ve kent yakın çevresindeki yeşil alanların oluşturduğu yeşil altyapının kompozisyonu, konfigürasyonu ve değişiminin analizi, birçok bilimsel araştırmaya konu olmuştur (örneğin Kong ve ark. (2005), Uy ve Nakagoshi (2007), Zhou ve Wang (2011), Emecan (2015), Yıldırım ve Ortaçeşme (2016)).

İzmir kenti, 1950'li yıllardan sonra hızlı bir kentleşme sürecine girmiştir. $\mathrm{Bu}$ süreçte metropol ilçelerden biri olan Bornova'nın kentsel peyzaj deseni zaman içinde önemli ölçüde değişmiştir. $\mathrm{Bu}$ araştırmada; Bornova kentsel peyzajı içindeki yeşil alanların strüktürünü ortaya koymak ve bu bağlamda planlama önerileri geliştirmek amacıyla 2014 yılındaki kentsel yeşil altyapısı (açık ve yeşil alan sistemi) peyzaj metrikleri kullanılarak analiz edilmiştir.

\section{Materyal ve Yöntem}

\subsection{Materyal}

Araştırma materyalini araştırma alanı ile birlikte 2014 tarihli WorldView2 (Pan+MS bundle) (50 cm yersel çözünürlük) uydu görüntüleri, 1/25 000 ölçekli topoğrafik haritalar, bu haritalara ait sayısal yükseklik verisi oluşturmaktadır.

Araştırma alanı Bornova ilçesinin $82.10 \quad \mathrm{~km}^{2}$ büyüklüğ̈̈ndeki kentsel gelişme alanıdır ( $38^{\circ} 34^{\prime} 21^{\prime \prime}$ ve $38^{\circ} 21^{\prime}$ $51^{\prime \prime}$ Kuzey, $27^{\circ} 09^{\prime} 10^{\prime \prime}$ ve $27^{\circ} 20^{\prime} 58^{\prime \prime}$ Doğu) (Şekil 1). Türkiye İstatistik Kurumu 2015 yılı Adrese Dayalı Nüfus Kayıt Sistemi veri tabanına göre toplam nüfusu, 435 162'dir (TÜİK 2015).

1900'lerin başlarına kadar İzmir kentinin bir banliyösü konumunda olan Bornova o y1llarda çoğunlukla tüccar ailelerden oluşan Levantenlerin yaşadığı büyük bahçeli villaların dışında, büyük ölçüde tarım alanlarıyla kaplıydı. 1960'li yıllardan itibaren İzmir kentinde yaşanan hızlı kentleşme sureci, Bornova'da da benzeri şekilde yaşanmış, tarım alanları ve bahçeli konutlar yerlerini çok küçük ya da hiç bahçesi olmayan apartman blokları tarafindan karakterize edilen yoğun dokulu bir kentsel yerleşime bırakmıştır (Hepcan ve ark. 2013).

\subsection{Yöntem}

Yöntem, veri üretimi ve veri analizi aşamalarından oluşmaktadır. Veri üretimi aşamasında; topoğrafik harita, sayısal yükseklik verileri, WorldView2 ve IKONOS (2005) uydu görüntülerinden yararlanılmıştır. Sayısal yükseklik modeli, 10 metre hassasiyetli sayısal yükseklik verilerinden ArcInfo 10 (ESRI 2011) yazılımı 3D Analyst modülü kullanılarak üretilmiştir. WorldView2 uydu görüntüleri kamera kalibrasyon bilgileri, sayısal yükseklik modeli ve IKONOS uydu görüntüsünden yararlanılarak ERDAS 9.1 Professional (Leica Geosystems 2006) yazılımı kullanılarak ortorektifiye edilmiştir. Ortorektifiye görüntü üretiminde yer kontrol noktaları IKONOS görüntüsü üzerinden elde edilmiş ve her bir çerçeve için ortalama 20-25 yer kontrol noktası seçilmiştir. Ortorektifikasyon işlemi tamamlanan görüntülerden mozaik görüntü elde edilmiş ve arazi kullanım haritası bu mozaik görüntüden 2. düzey CORINE (Coordination of Information on the Environment) alt sinifları esas alınarak, ekran sayısallaştırması yoluyla üretilmiştir (Bossard ve ark. 2000). Sınıflandırma, arazi gözlemleriyle desteklenmiştir.

Araştırma alanında kentsel açık ve yeşil alan sistemini oluşturan bileşenlerden parça ve koridorların tipolojileri tanımlanmış, bu kapsamda arazi kullanım haritaları; (1) yapılı alanlar (yapılı alanlar, endüstriyel alanlar, otoyollar, hava alanı, çöp depolama alanları, taş ocakları), (2) bitkilendirilmiş kentsel yeşil alanlar (kent parkları, okul-kampüs bahçeleri, mezarlıklar, oyun alanları, su kıyısı rekreasyon alanları, konut bahçeleri, yol kıyısı vejetasyonları, bitkilendirilmiş parçalar, tarım alanları, zeytinlik alanlar ve meyve bahçeleri, su kanalları) ve (3) doğal karakterli kentsel yeşil alanlar (maki, frigana ve orman vejetasyonları, ağaçlandırma alanları, boş/tahrip olmuş alanlar, akarsu koridoru) olmak üzere 3 sinıf altında yeniden sınıflandırılmış, veri hassasiyeti $5 \mathrm{~m} \mathrm{x} 5 \mathrm{~m}$ olarak belirlenmiştir.

Kentsel açık ve yeşil alan sistemini oluşturan elemanların strüktürel analizinde; sınıf alanı (CA), parça sayısı (NP), peyzajın oranı (PLAND), peyzaj şekil indeksi (LSI), ortalama parça büyüklüğü (AREA_MN), yakınlık indeksi (PROX_AM), süreklilik indeksi (GYRATE_AM), mesafe indeksi (ENN_AM) olmak üzere sekiz adet peyzaj indeksi/metriği ve FRAGSTATS 3.4 yazılımı kullanılmıştır (McGarigal ve Marks 2003; Botequilha Leitao ve ark. 2006).

\section{Bulgular}

Büyük ölçüde Bornova ovası üzerinde gelişme gösteren, temelde konut ve sanayi alanları tarafindan karakterize edilen ilçenin yapılaşmış alanı $44.91 \mathrm{~km}^{2}$ büyüklüğe sahip olup kentsel gelişme alanının \% 54.7'sini oluşturmaktadır. Kent merkezi ve yakın çevresinde binalar çok katlı ve bitişik nizamda inşa edilmiştir. 18. ve 19. yüzyılda inşa edilen Levanten evleri dışında geniş bahçeli müstakil konutlar bulunmamaktadır. Buna karşılık Bornova'nın yeni gelişme alanlarında küçük bahçelerle çevrili çok katlı apartman ya da 2-3 katlı müstakil konut tiplerine rastlanmaktadır.

Bornova'da kentsel açık ve yeşil alan sistemi oluşturma potansiyeline sahip parça ve koridorların kentsel gelişme alanı içindeki oranı \% 45 'tir. $35.56 \mathrm{~km}^{2}$ alan kaplayan parçaların kentsel gelişme alanındaki oranı yaklaşık \% 43, koridorların ise 


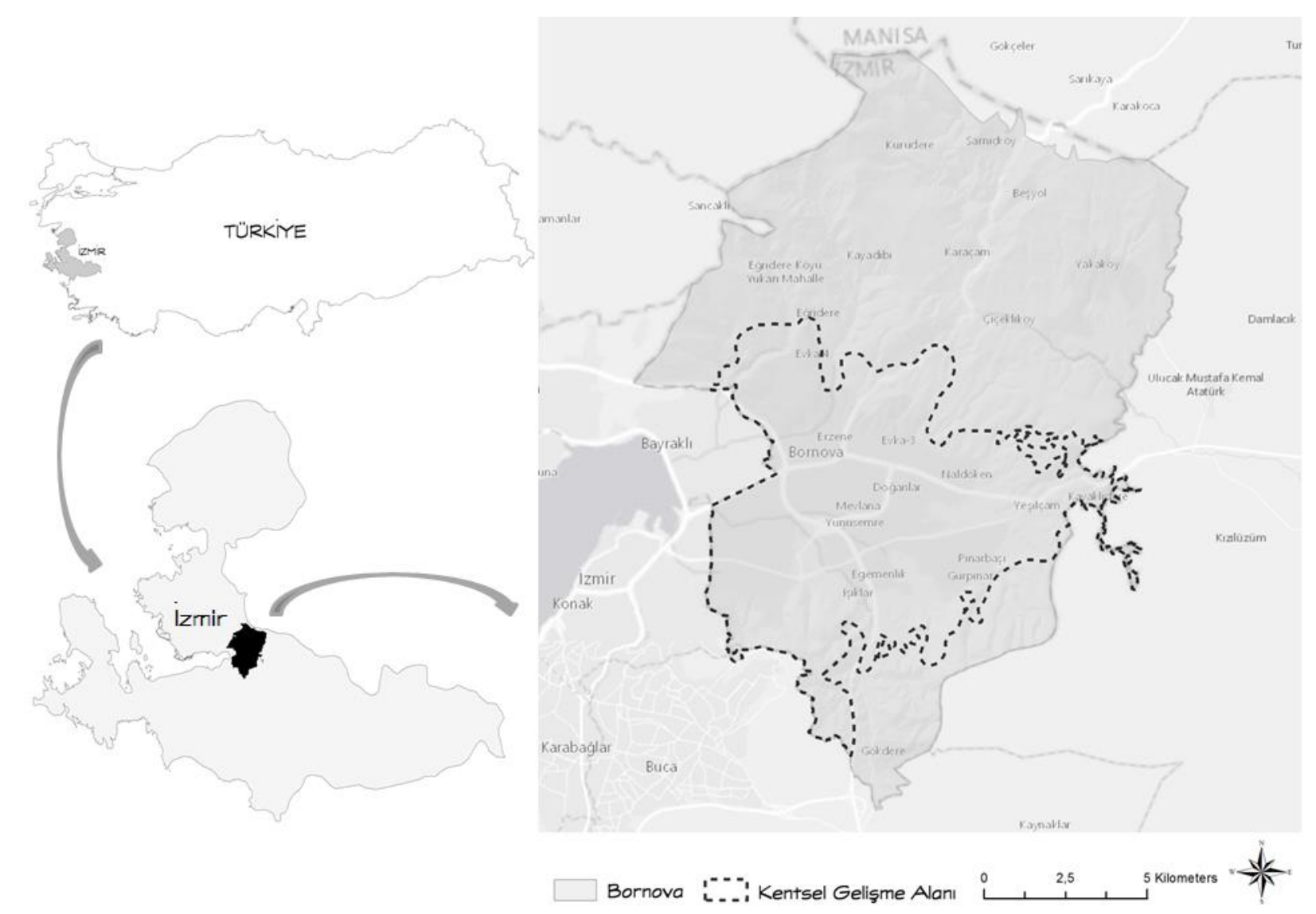

Şekil 1. Araştırma alanının coğrafi konumu.

Figure 1. Location of the study area.

yaklaşık \% 2'dir (Şekil 2) (Çizelge 1-2). Parçalar tipolojilerine göre; tarım arazisi, zeytinlik, kampüs, mezarlık, bahçe, doğal alan, açık alan ve park olarak sınıflandırılmıştır (Çizelge 1). Frigana, maki ve kızılçam ormanları tarafından karakterize edilen doğal vejetasyon örtüsüne sahip parçalar parça tipolojileri içinde baskın arazi örtüsünü oluşturmaktadır. Ağırlıklı olarak yapılaşmış alanın çeperlerindeki yamaçları kaplayan bu alanlar parçalı bir yapı sergilemektedir.

Zeytinlikler, parça tipolojileri içinde büyüklük açısından ikinci sırada yer almaktadır. Geniş zeytinlikler büyük ölçüde doğal alanlara komşu olan ve yapılaşmış alanı çevreleyen yamaçlar üzerinde yer almakta ve $6.27 \mathrm{~km}^{2}$ lik bir alan kaplamaktadır (Şekil 2; Çizelge 1).

Açık alanlar, yapı adaları arasındaki boş alanlar ya da yol kıyısında bulunan henüz yapılaşmamış alanlar olup, kentsel peyzajda toplamda $4 \mathrm{~km}^{2}$ büyüklügüünde alan kaplamaktadır. Ağırlıklı olarak, ilçenin güneyinde ve doğusunda düze yakın ve az eğimli alanlarda geniş parçalar şeklinde dağılım gösteren bu alanlar doğal vejetasyonun zarar gördüğü ya da tarım arazilerinde tarımsal üretimin bırakıldığı parçalardır. Üzerinde bitki örtüsü bulunmamakta veya mevsimsel otsu vejetasyon gelişme göstermektedir.

Bornova ilçesinin büyük ölçüde tarım arazileri üzerinde yayıldığı düşünüldüğünde önceleri kentsel doku içindeki geniş parçalar kaplayan tarım alanlarının görünümü, yapı adaları arasında kalan küçük parçalar şeklindedir.
Ege ve Yaşar Üniversitelerinin kampüsleri ilçenin merkezinde yaklaşık $3 \mathrm{~km}^{2}$ büyüklüğünde alan kaplamaktadır. Yaşar Üniversitesi kampüsü tek, Ege Üniversitesi kampüsü ise Ankara Caddesi ve Bornova Caddesi nedeniyle üç bölümden oluşmaktadır.

Bahçeler; kamu binaları, ticaret alanları ve konut bahçelerinden oluşmaktadır. Bornova kentsel gelişme alanında düzensiz bir dağılım gösteren bu alanların kentsel gelişim alanı içinde kapladığ 1 yer toplamda $2.12 \mathrm{~km}^{2}$ dir. Konut bahçeleri nispeten geniş parsellerden oluşurken, apartman, kamu binaları ve ticaret merkezlerinin bahçeleri küçük parseller şeklindedir (Şekil 1; Çizelge 1).

Kent parklarının kentsel gelişme alanındaki toplam büyüklüğü $1 \mathrm{~km}^{2}$ dir. Bornova'daki parklar Büyükpark ve Âşık Veysel Rekreasyon Alanı dışında büyük ölçüde orta ve küçük boyutlardaki mahalle parklarınca karakterize edilmektedir. Parça tipolojisinde en küçük alan $0.76 \mathrm{~km}^{2}$ ile mezarlıklara aittir. Kent merkezindeki eski yabancı mezarlıkları dışındaki tüm mezarlıklar kentin çeperlerinde yer almaktadır (Şekil 2; Çizelge 1).

Bornova'da koridorlar tipolojik olarak dört alt gruba ayrılmıştır. Kentsel gelişim alanında oldukça küçük bir alan kaplayan bu alanlar; akarsu koridoru, su kanalı, doğal koridor ve açık alandır (Çizelge 1). Akarsu koridorlarının bir bölümü doğal yataklarında akmakta olup, kent içinden geçen bölümleri açık ya da kapalı beton kanallara alınmıştır. 

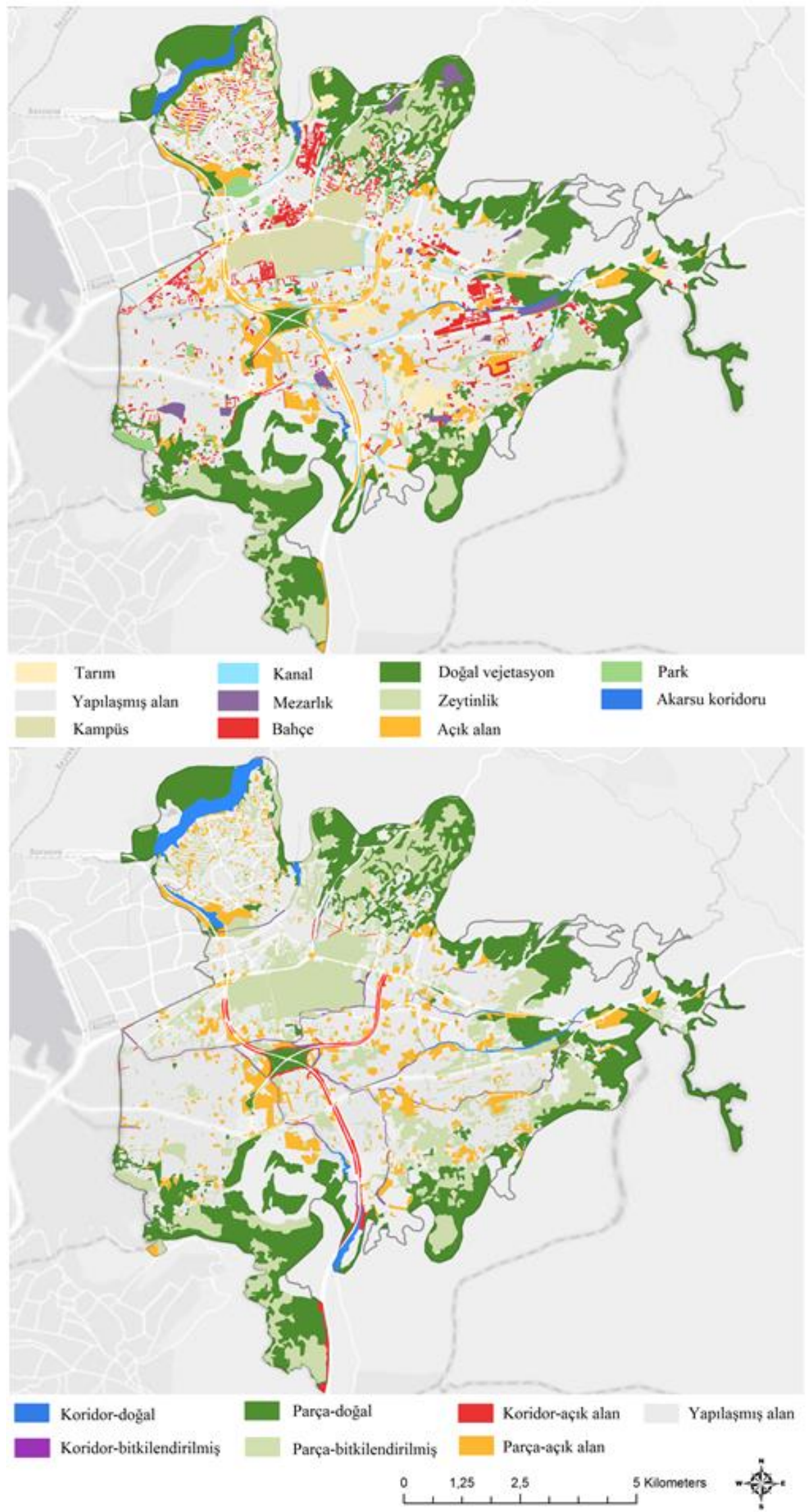

Şekil 2. Kentsel açık yeşil alan sistemi bileșenleri.

Figure 2. The elements of the urban green infrastructure. 
Çizelge 1. Bornova kentsel matrisinde bulunan yeşil alt yapı elemanları. Table 1. The elements of green infrastructure in the urban matrix of Bornova.

\begin{tabular}{llc}
\hline & Tipoloji & Alan $\left(\mathbf{k m}^{\mathbf{2}}\right)$ \\
\hline \multirow{4}{*}{ Parça } & Zeytinlik arazisi & 1.48 \\
& Kampüs & 6.27 \\
& Mezarlık & 2.95 \\
& Bahçe & 0.76 \\
& Doğal vejetasyon & 2.12 \\
Koridor & Açık alan & 16.27 \\
& Park & 4.07 \\
& Akarsu koridoru & 1.00 \\
& Su kanalı & 0.57 \\
& Doğal vejetasyon & 0.44 \\
& Açık alan & 0.72 \\
\hline
\end{tabular}

Çizelge 2. Analiz sonuçları.

Table 2. Results of the analysis.

\begin{tabular}{lccc}
\hline & Yapılaşmış alan & Parça & Koridor \\
\hline CA & 4491.23 & 3495.86 & 223.02 \\
NP & 42.00 & 1845.00 & 194.00 \\
PLAND & 54.70 & 42.57 & 2.71 \\
LSI & 37.67 & 39.75 & 28.59 \\
AREA_MN & 106.93 & 1.89 & 1.14 \\
GYRATE_AM & 3304.00 & 520.33 & 498.80 \\
PROX_AM & 4535.11 & 3961.88 & 75.27 \\
ENN_AM & 12.99 & 23.71 & 287.24 \\
\hline
\end{tabular}

Bunun dışındaki küçük dereler ise kentsel gelişim sürecinde üzerleri kapatılarak yapı adalarına dönüşmüştür. Doğal koridorlar, çizgisel/doğrusal şekil özellikleri nedeniyle koridor olarak tanımlanan doğal vejetasyon örtüsüyle kaplı alanlardır. Açık alan niteliğindeki koridorlar ise çoğunlukla karayolu kenarlarında bulunan, doğrusal-koridor özelliği taşıyan, ağırlıklı olarak üzerinde otsu bitkiler barındıran çok az sayıda da olsa çok yıllık odunsu bitki barındıran alanlar tarafından karakterize edilmektedir.

Strüktür analizlerinde doğal karakterli ve bitkilendirilmiş parça sayısı (NP) 1845 olarak saptanmıştır. Büyüklük açısından oldukça çeşitlilik gösteren bu alanların ortalama parça büyüklüğü değeri ise (AREA_MN) 1.89'dir. Bu rakamlar çok parçalı bir yapıya işaret etmektedir (Şekil 2; Çizelge 2).

Parça ve koridorların süreklilik indeksi (GYRATE_AM) değeri birbirine yakın iken, yapılaşmış alanın altı kat daha fazladır. $\mathrm{Bu}$ durum açık ve yeşil alan sistemi bileşenlerinin kentsel peyzajdaki sürekliliğinin düşük olduğunun bir göstergesidir. Kentsel peyzaj deseninde açık ve yeşil alan sistemini oluşturabilecek geniş ve bütünlük gösteren parçalar ağırlıklı olarak gelişme alanının çeperlerinde yer almaktadır. Küçük ve orta büyüklüklerdeki parçaların ise kentsel peyzaj içinde düzensiz bir dağılım gösterdiği görülmektedir. Kentsel doku içinde bulunan en büyük parçalar Ege Üniversitesi Kampüsüne ait parçalardır.
Bornova'nın kentsel gelişim alanı içinde 194 adet koridor tanımlanmıştır. Kentsel doku içinde oldukça küçük bir orana sahip bu koridorların ortalama parça büyüklüğünün 1.14 olmas1, koridorların küçük boyutlarda olduğunu ifade etmektedir. Parçaların yakınlık indeksi değeri (PROX_AM) 3961.88 iken koridorların yakınlık indeksi değerinin 75.27 olması, kentsel gelişim dokusu içindeki koridorların birbirine uzak konumlandığını, dolayısıyla koridorlar arasında fiziksel olarak yalıtılmışlığın fazla olduğunu göstermektedir. Benzer şekilde mesafe indeksi (ENN_AM) değerinin yüksek olması koridorlar arasındaki mesafelerin fazla olduğunu teyit eden diğer bir göstergesidir (Şekil 2; Çizelge 2).

Kentsel gelişim alanının tamamı değerlendirildiğinde; yapılı alan ve parçalar mesafe indeksi açısından yakın değer almıştır. Koridorların mesafe indeksi değeri ise yapılı alan ve parçaların yaklaşık 15 katıdır. Bu durum, açık ve yeşil alan sistemini oluşturan parçalar arasındaki mesafelerin az, koridorlar arasındaki mesafelerin yüksek olduğunu ifade etmektedir (Çizelge 2).

Kentsel peyzaj desenini oluşturan bileşenlerin 28.59 ile 37.67 arasında değişen peyzaj şekil indeksi (LSI) değerlerinde dikkate değer bir farklılık olmaması, bu peyzaj elemanlarının şekil yönünden basit bir yapıya sahip olduğu anlamına gelmektedir (Çizelge 2).

\section{Tartışma ve Sonuç}

$\mathrm{Bu}$ araştırmada; Bornova ilçesinin güncel durumuna 1 şı tutmas1 amacıyla 2014 yılındaki kentsel yeşil alt yapısı peyzaj ekolojisi temelli bir yaklaşımla peyzaj metrikleri kullanılarak analiz edilmiştir.

Araştırma sonuçları açık ve yeşil alanların parçalı bir yapı ve düzensiz bir dağılıma sahip olduğunu, Bornova'da ekolojik ve rekreasyonel işlevlere sahip kentsel bir açık ve yeşil alan sisteminin (açık ve yeşil alanlar ağı ya da yeşil altyapı) bulunmadığını göstermiştir. $\mathrm{Bu}$ durum birçok kentin ortak sorunudur, örneğin Uy ve Nakagoshi (2007) Vietnam'in başkenti Hanoi'deki yeşil alanların oluşturduğu desenin küçük parçalardan oluşan parçalı bir yapıya sahip olduğunu belirlemiştir. Benzer şekilde Kong ve ark. (2005) Jinan (Çin) kent merkezinde yeşil alanların düzensiz bir dağılım desenine sahip olduğunu saptamıştır.

Bununla birlikte kentsel gelişme alanının yaklaşık \% 45'inin yeşil altyapı sisteminin bir parçası olabilecek potansiyele sahip olduğu belirlenmiştir. Diğer bir değişle Bornova için günümüzde yeşil altyapının bileşenleri büyük ölçüde mevcut olup, yapılması gereken bu elemanların çok işlevli ve birbiriyle fiziksel-işlevsel olarak bağlantılı bir sisteme dönüştürülmesi/bir yeşil altyapının oluşturulmasıdır. Farklı tipolojilere sahip bu peyzaj elemanlarının \%43'ü parça, \%2'si ise koridor niteliğindedir. Parçaların \% 59'u, koridorların ise \% 65'i doğal karakterlidir. Burada vurgulanması gereken nokta; bunların kentsel peyzajda düzensiz bir dağılım göstermesi ve büyük bölümünün kentsel peyzaj dokusu içinde değil, çeperlerinde yer almasıdır (Şekil 2). Bu sonuçlar Tokuş (2012)'un Sarıyer (İstanbul) ilçesindeki yeşil ağ elemanlarını analiz ettiği (\% 82 parça, \% 4 koridor) çalışmanın sonuçlarıyla benzerlik göstermektedir.

Kentsel peyzajların içinde veya kıyısında bulunan parçalanmamış, bütünlüğünü koruyan geniş parçalar şeklindeki doğal alanlar, türlerin kentsel doku boyunca hareket etmesine olanak sağlar (Forman 2008). Bornova'nın çeperinde yer alan 
\% 58 oranındaki doğal alanlar, ilçe için bu bağlamda ciddi bir potansiyel sunmaktadır.

İlçe, günümüzde kuzey ve doğudaki eğimli alanlar üzerine yayılma eğilimi göstermektedir. Bu durum, Çevre Düzeni Planı'nda kentsel gelişme alanı olarak tanımlanan çeperlerdeki bu doğal alanları yapılaşmış alanlara dönüşme riski altında bırakmaktadır. Bu alanların kaybı Bornova için önemli olumsuz sonuçlar doğuracak ve yukarıda sözü edilen açık ve yeşil alan sistemi oluşturma ve kentsel peyzaj içinden başlayan ve çeperlere doğru yayılan yeşil yollar ya da ekolojik koridorlar tesis etmeyi neredeyse imkânsız hale getirecektir.

İzmir Büyükşehir genelinde olduğu gibi Bornova'da da kent parkları ilçenin oldukça küçük bir bölümünü kaplamaktadır (Hepcan 2013). Parklar, özellikle yapılaşmanın yoğun olduğu kentsel peyzajlarda biyolojik çeşitliliğin muhafaza edilmesinde çok önemlidir (Cornelis ve Hermy 2004). Bornova'daki parkların büyük bölümü küçük boyutlu parklar şeklindedir. Dolayısıyla Büyükpark ve Aşık Veysel Rekreasyon Alanı ilçenin en geniş kent parkları olarak potansiyel açık ve yeşil alan sisteminin/ağının en önemli bileşenleri arasındadır. Mevcut yapılaşmış kent dokusunda yeni açık ve yeşil alanlar tesis etmek neredeyse imkânsızdır. Ancak yeni açık ve yeşil alanlar oluşturmak veya mevcutları genişletmenin bir yolu kentsel dönüşüm uygulamalarıdır. Bunu bir firsat olarak görüp açık ve yeşil alan miktarının arttırmak, akarsu koridorlarını yeniden ele almak ve bir açık-yeşil alan sistemi kurmak olasıdır.

Kentsel peyzajlardaki tarım arazileri üretim dışında, insanları toprakla buluştururken kent halkına rekreasyonel olanaklar sağlar, habitat oluşturarak yaban hayatını destekler ve sürdürülebilir kentlerin gelişmesine katkıda bulunur (Coşkun Hepcan 2014). Forman (2014), Londra ve Chicago gibi bazı kentlerde kentsel peyzaj dokusu içinde doğal vejetasyon örtüsüyle kaplı geniş ve bütünlüğünü koruyan parçaların bulunmaması nedeniyle, tarım alanlarının kentsel yabanıl türlerin başlıca habitatları konumunda olduğunu vurgulamaktadır. Bu bağlamda Bornova'da yapılaşmış alanda hemen hiç kalmasa bile çeperdeki tarım alanlarının korunması büyük önem taşımaktadır.

Kentsel peyzajlardaki bahçeler, barındırdıkları biyolojik çeşitlilik ve ekolojik işlevleriyle açık ve yeşil alan sistemi açısından önemli elemanlar olarak kabul edilmektedir (Akinnifesi ve ark. 2010; Beumer ve Martens 2015; Williams ve ark. 2015). Özellikle kent merkezinde bulunan Levanten villalarının/evlerinin bahçeleri kent ekolojisi ve kentsel yaban hayatı açısından çok değerli habitatlardır (özellikle kuş türleri bakımından). Bu bahçelerin mevcut haliyle ve özelikle yap1 yoğunluğunu arttırmadan korunmaları Bornova için oldukça önemli bir kazanım olacaktır.

Ege Üniversitesi Kampüsü, Bornova'da en geniş bitkilendirilmiş alanı oluşturmaktadır. Kampüsün diğer bölümlerinde yoğun bir yapılaşma olsa da, lojmanlar yerleşkesinde bulunan parçalanmamış fistık çamı koruluğu, sağladığ 1 ekolojik hizmetler bağlamında ilçenin açık ve yeşil alan sisteminin çok değerli bir bileşenidir. Kampüste yürütülen bazı bilimsel çalışmalarda (örn Kurun 2001; Kaya 2005; Coşkun Hepcan ve Hepcan 2017) bu alanların kuş türleri açısından önemli habitatlar olduğu belirlenmiştir.

Benzer şekilde mezarlıklar da açık yeşil alan sistemi açısından dikkate değer potansiyele sahiptir. Adams ve ark. (2006) özellikle eski mezarlıkların, yaşlı ağaçları içermesi nedeniyle birçok yabanıl türe beslenme ve barınma ortamı sağlayarak kentin biyolojik çeşitliliğine katkıda bulunduğunu belirtmektedir. Bornova'da yapılaşmış alan içindeki kalan eski mezarlıkların bu anlamda önemini vurgulamak gereklidir.

Açık ve yeşil alan potansiyeli taşıyan koridor türleri, ilçede çok az (\% 2) bir alan kaplamaktadır. Bu nedenle çeşitli form ve genişliklerde bitkilendirilmiş yeni koridorların oluşturulmasına gereksinim vardır. Little (1995)'ın vurguladığı gibi, var olan ya da oluşturulan koridorların bağlantısız koridorlar olarak tek kalmalarını önlemek için doğal ya da bitkilendirilmiş parçalarla fiziksel olarak ilişkilendirilmesi önemlidir. $\mathrm{Bu}$ kapsamda Bornova'da 10 metre ve üzerindeki genişliğe sahip sokakların ve çevreyolunun ağaçlandırılmasıyla $112 \mathrm{~km}$, demiryolu çevresinin ağaçlandırılmasıyla $1.5 \mathrm{~km}$, akarsu yataklarının iyileştirilmesiyle $17 \mathrm{~km}$ ve enerji iletim hatlarının altında kalan alanların bitkilendirilmesiyle $4 \mathrm{~km}$ uzunluğunda koridorların oluşturulması ve bu sayede mevcut yeşil parçaların bir bölümüyle fiziksel bağlantıların kurulması mümkündür.

$\mathrm{Bu}$ araştırma sonucunda elde edilen bulgular özetle yorumlandığında; kentte bir yeşil alt yapı sisteminin bulunmadığı, niteliksel ve niceliksel açıdan açık ve yeşil alanların kentsel peyzaj içindeki durumun yeterli olmadığı, ancak kentin içinde olmasa da çeperlerinde yeşil altyapı sisteminin parçası olabilecek yeşil alanların bulunduğu ortaya çıkmaktadır.

Sonuç olarak, öncelikle kentin çeperlerindeki yukarıda adı gecen bu stokun olabildiğince korunarak bir açık ve yeşil alan sistemi oluşturmak için kullanılması gereklidir. Ayrıca kentteki yapılaşmış alan içinde de mevcut yeşil alanların kalitesini arttırma yönünde yapılabileceklerin yansıra kentsel dönüşüm uygulamaları da bazı yeni firsatlar sunmaktadır. Bu uygulamalar yeni ve olabildiğince büyük boyutlu açık ve yeşil alanlar yaratmak ve bunları çeperdeki alanlara doğal ve/veya insan yapısı koridorlar vasıtasıyla bütünleştirmek için kullanılabilir. Bunları hayata geçirebilmede kilit nokta ise, bir açık ve yeşil alan planlaması yapılmasıdır. Planlama ile üretilecek açı ve yeşil alanlar başta yaban hayatı koruma ve geliştirme, yağış suyu yönetimi gibi pek çok ekosistem hizmeti açısından çok daha işlevsel olacak, kent içi ve yakın çevresinde bir omurga işlevi görecektir.

\section{Teşekkür}

$\mathrm{Bu}$ araştırma 2013-ZRF-14 no.lu proje kapsamında hazırlanmıș olup, projeyi destekleyen E.Ü. Bilimsel Araştırma Projeleri Komisyonuna teşekkür ederiz.

\section{Kaynaklar}

Adams CE, Lindsay KJ, Ash SJ (2006) Urban wildlife management, Taylor \& Francis Group, p. 311.

Akinnifesi FK, Sileshi GW, Ajayi OJ, Akinnifesi AI, de Moura EM, Linhares JFP, Rodrigues I (2010) Biodiversity of the urban homegardens of São Luís city, Northeastern Brazil, Urban Ecosystems 13: 129-146.

Benedict MA (2000) Green infrastructure: a strategic approach to land conservation, American Planning Association PAS Memo.

Beumer C, Martens P (2015) BIMBY's first steps: a pilot study on the contribution of residential front-yards in Phoenix and Maastricht to biodiversity, ecosystem services and urban sustainability, Urban Ecosystems, DOI 10.1007/s11252-015-0488-y.

Bossard M, Feranec J, Otahel J (2000) CORINE land cover, technical guide-addendum 2000. Report No. 40. Retrieved from European Environmental Agency. http://europa.eu. Erişim Nisan 2007. 
Botequilha Leitao A, Miller J, Ahern J, McGarigal K (2006) Measuring landscapes: a planner's handbook. Island Press, Washington, pp. 118.

Cornelis J, Hermy M (2004) Biodiversity relationships in urban and suburban parks in Flanders, Landscape and Urban Planning 69: 385-401.

Coşkun Hepcan Ç (2014) Analyzing urban agriculture pattern; the case of Bornova, 25th International Scientific Expert Congress on Agriculture and Food Industry, 25-27 September 2014 Çeşme, 25 ${ }^{\text {th }}$ International Scientific Expert Congress on Agriculture and Food Industry Proceedings Volume I, Oral Presentations: 173-176.

Coşkun Hepcan Ç, Hepcan Ş (2017) Assessing the avian diversity of the urban green areas: the case of Bornova, Izmir, Journal of Environmental Protection and Ecology 18(1): 390-398.

Davies C, MacFarlane R, McGloin C, Roe M (2015) Green infrastructure planning guide technical report. DOI: 10.13140/RG.2.1.1191.3688.

Emecan Y (2015) Peyzaj Metrikleri Kullanarak Sarıyer Bölgesi Örnek Alanındaki Peyzaj Değişimlerinin Belirlenmesi ve Değerlendirilmesi. Yüksek Lisans Tezi, İstanbul Üniversitesi Fen Bilimleri Enstitüsü Peyzaj Mimarlığı Anabilim Dalı, s. 168.

Esbah H, Cook EA, Ewan J (2009) Effects of increasing urbanisation on the ecological integrity of open space preserves. Environmental Management 43: 846-862.

ESRI (2011) ArcView 9.10 Software, Environmental systems research institute, CA.

European Commission (2013) European Union building a green infrastructure for Europe, ISBN 978-92-79-33428-3.

European Environment Agency (2011) Green infrastructure and territorial cohesion; the concept of green infrastructure and its integration into policies using monitoring systems. EEA Technical report No: 18/2011. ISSN: $1725-2237$.

Forman TT (2008) Urban regions: ecology and planning beyond the city, Cambridge University Press, New York.

Forman TT (2014) Urban ecology science of cities, Cambridge University Press, England, p. 462.

Fung T, So LLH, Chen Y, Shi P, Wang J (2008) Analysis of green space in Chongqing and Nanjing, cities of China with ASTER images using object-oriented image classification and landscape metric analysis, International Journal of Remote Sensing 29(24): 7159-7180.

Hepcan S, Kaplan A, Özkan MB, Küçükerbas EV, Yigit EM, Türel HS (2006) Public space networks as a guide to sustainable urban development and social life: a case study of Mugla, Turkey. Int J Sust Dev World 13: 1-15.

Hepcan Ş (2013) Analyzing the pattern and connectivity of urban green spaces: A case study of Izmir, Turkey, Urban Ecosystems 16: 279293.
Hepcan Ş, Coşkun Hepcan Ç, Kılıçaslan Ç, Özkan MB, Koçan N (2013) Analyzing landscape change and urban sprawl of a Mediterranean coastal landscape: A case study of Izmir, Turkey. Journal of Coastal Research 29(2): 301-310.

Kaya C (2005) Ege Üniversitesi kampüsünde yaşayan kuşların araştırılması, diploma çalışması, Ege Ü. Fen Fakültesi Biyoloji Bölümü Zooloji Anabilim Dalı, İzmir, s. 40.

Kong, F, Nakagoshi, N, Yin, H, Kikuchi, A (2005) Spatial gradient analysis of urban green spaces combined with landscape metrics in Jinan City of China, Chinese Geographical Science 15(3): 254-261.

Kurun M (2001) EÜ kampüsündeki kuş türlerinin biyolojileri hakkında araştırmalar, YL Tezi, Ege Üniversitesi Fen Bilimleri Enstitüsü Biyoloji Anabilim Dalı, İzmir, s. 49.

Leica Geosystems (2006) ERDAS Imagine Professional 9.1. Software, Leica Geosystems, Sweden.

Little CE (1995) Greenways for America. The Johns Hopkins Press Ltd. London, ISBN 0-8018-5140-8.

McGarigal K, Marks BJ (2003) FRAGSTATS. Spatial pattern analysis program for quantifying landscapes structure. Version 3.4 Oregon State University, Corvallis.

Steiner F (2011) Landscape ecological urbanism: origins and trajectories. Landscape and Urban Planning 100: 333-337.

Tokuş M, Tuncay Eşbah H (2010) Ekolojik ağlar yeşil yollar ve yeşil altyapı kavramlarının tariflenmesi, ortaklık ve farklılıklarının ortaya konulması, Peyzaj Mimarlığı IV. Kongresi 21-24 Ekim 2010 Selçuk İzmir, Bildiriler Kitabı: 501-508.

Tokuş M (2012) Kentsel Yeşil Ağlar: Sarıyer Örneği, Yüksek Lisans Tezi, İstanbul Teknik Üniversitesi Fen Bilimleri Enstitüsü Peyzaj Mimarlığı Anabilim Dalı, İstanbul, s. 163.

TÜİK (2015) Adrese dayalı nüfus kayıt sistemi (ADNKS) Sonuçları, http://tuikapp.tuik.gov.tr/adnksdagitapp/adnks.zul, Erişim Mayıs 2016.

Uy PD, Nakagoshi N (2007) Analyzing urban green space pattern and eco-network in Hanoi, Vietnam. Landscape Ecol Eng (2007) 3: 143-157. DOI 10.1007/s11355-007-0030-3.

Williams RL, Stafford R, Goodenough, AE (2015) Biodiversity in urban gardens: Assessing the accuracy of citizen science data on garden hedgehogs, Urban Ecosystems 18: 819-833.

Yıldırım E, Ortaçeşme V (2016) Manavgat Nehri Havzası'ndaki Peyzaj Değişiminin Peyzajların Korunması, Planlanması ve Yönetimine Yönelik Değerlendirilmesi. Mediterranean Agricultural Sciences, 29(2): 65-72.

Zhou X, Wang YC (2011) Spatial-temporal dynamics of urban green space in response to rapid urbanization and greening policies Xiaolu. Landscape and Urban Planning 100: 268-277. 